\title{
Environmental Monitoring System by Using Unmanned Aerial Vehicle
}

\author{
Mohamed Aboubakr, Ahmed Balkis, Ali-Abou ElNour, and Mohammed Tarique \\ Department of Electrical Engineering \\ Ajman University, P.O. Box 2202 \\ Fujairah, United Arab Emirates \\ E-mail: m.tarique@ajman.ac.ae
}

Received: September 1, 2017 Accepted: December 10, 2017 Published: December 31, 2017

DOI: 10.5296/npa.v9i3-4.12021

URL: http://dx.doi.org/10.5296/npa.v9i3-4.12021

\begin{abstract}
This paper presents a reliable and low cost environmental monitoring system. The system uses an Unmanned Ariel Vehicle (UAV) equipped with a set of sensors, microcontroller, wireless system, and other accessories. The system consists of two systems namely air quality monitoring system and water quality monitoring system. The air quality monitoring system consists of a set of gas sensors and microcontroller. This system measures the concentration of greenhouse gases at different altitudes under different environmental conditions. On the other hand, the water quality monitoring system consists of a set of water quality sensors, microcontroller, and water sampling unit. This system collects water samples from off-shore and on-shore water sources and measures water quality parameters. The present system is capable of recording the measured data in an onboard SD card. It is also able to send data to a ground monitoring unit through a wireless system. To ensure reliability in measurement the sensors are calibrated before deployment. Finally, the system is upgradable and reconfigurable. The system has been tested to measure air and water quality at different local areas. Some these measured data are also presented in this paper.
\end{abstract}

Keywords: Unmanned Aerial Vehicle, greenhouse gas, air pollution, water pollution, sensors, networks, wireless communication. 


\section{Introduction}

Now-a-days, environmental pollutions has become a critical issue. Air pollution and water pollution are playing the key roles in this regard. Recently, air pollution, caused by greenhouse gases (GHGs), is considered responsible for much concerned global warming. The GHGs absorb radiation within the thermal infrared range and hence absorb the heat produced by the Sun. These also trap long-wave radiation emitted by the Earth's surface and make our planet habitable [1]. These GHGs has their own concentration level in the atmosphere. Human activities, specifically consumption of fossil fuel, are increasing the amount of the GHGs including carbon dioxide $\left(\mathrm{CO}_{2}\right)$ and methane $\left(\mathrm{CH}_{4}\right)$ in the atmosphere. These two major GHGs are causing the greenhouse effect to trap more heat on the Earth [2] and hence causing the global warming. A number of researches show that global warming is adversely affecting our existing ecosystem and biodiversity [1-5]. If the greenhouse gas emission continues at this present rate, the Earth's surface temperature could exceed all the historical values as early as 2047 [6].

Considering the long-term environmental and social effects of greenhouse gases [7] many developed and developing countries already came forward and initiated numerous renewable energy and eco-friendly projects. Major business organizations have taken both preventive and corrective measures to reduce the production of greenhouse gases [8]. In order to justify these corrective measures as well as to aware people about the global warming accurate data about the GHGs are still needed. These data should include both temporal and spatial variations of the greenhouse gas concentrations at different atmospheric levels.

Like air pollution, water pollution also has drawn considerable attention in the recent years. High quality water is very essential for drinking and household purposes. It is also important for other purposes including power generation, food production, fisheries, and recreational activities. Polluted water can cause disease outbreaks and hence can cause devastating effects on public health. Hence, high quality water is also important to promote socioeconomic development of a country [9]. The World Economic Forum listed poor quality water as a top global risk in January 2015 [10-11]. Some alarming facts are worthwhile to mention here. Around four million people die each year from water related diseases. One child dies from water related diseases in every 90 seconds [10]. Water pollution is primarily caused by biological and physicochemical contaminations. Biological contamination occurs due to the ingestion of water contaminated by human or animal fasces. On the other hand, physicochemical contamination arises from the chemical constituents. Preventive and corrective measures are usually initiated to reduce water pollution.

Biological contamination can be prevented by a series of treatment process and by proper management of water distribution system. The physicochemical contamination can be prevented by strictly monitoring and maintaining the chemical constituents of water at their acceptable limit. The contamination of water in distribution system is mainly caused by inadequate operation, maintenance, and quality control. In addition, stresses on water distribution system are worsening the problem. These stresses are caused by rapid urbanization, population growth, and aging distribution infrastructure. 
Many works have been done to monitor greenhouse gases and water quality till date. In order to measure greenhouse gas concentrations at different atmospheric level Unmanned Aerial Vehicle (UAV) based system has become very popular in the recent years. This paper presents an UAV based environmental monitoring system. A cheap Quadcopter has been used in this work instead of expensive high tech aircraft. The Quadcopter is equipped with sensors, microcontrollers, and other accessories. The system is consisting of two systems namely gas monitoring system and water quality monitoring system.

The gas monitoring system is able to measure the concentrations of greenhouse gases namely carbon dioxide $\left(\mathrm{CO}_{2}\right)$, methane $\left(\mathrm{CH}_{4}\right)$, nitrous oxide $\left(\mathrm{N}_{2} \mathrm{O}\right)$, water vapor $\left(\mathrm{H}_{2} \mathrm{O}\right)$, and ozone $\left(\mathrm{O}_{3}\right)$ at different altitudes (allowed by the local aviation authority). The water quality monitoring system is able to collect water samples from water sources and then measure the water quality parameters. This present system can play an important role in this region (i.e., Arabian Gulf areas). Because the groundwater is the main source of water in this region. Some other water sources also exist in this region. However, these water sources are located in remote places. Hence, water sampling using UAVs can play an important role to monitor the water quality in this region. The system is also able to send the data to a remote monitoring station. The system is also able to store the data in an on board SD memory card.

The rest of the paper is organized as follows. Some related works are presented in section 2. The methodology used in this work is presented in section 3. The system components and their costs are presented in the same section. Extensive experimental data are presented in section 4. This paper is concluded with section 5 .

\section{Related Works}

This section presents some recent works that are directly related to this work. Related gas measurement systems and water quality measurement systems are presented in two sub sections. This section also presents the limitations of existing related works and discusses the advantages of present system over other existing systems.

The UAVs have become popular to execute difficult and dangerous tasks in the recent years. They are being used in many applications including public safety, disaster management, scientific research, agriculture, and environment protection [12]. In these applications, the UAVs are not only saving time and money, but also they are saving lives and resources. Recently, commercially available UAVs have emerged as a new tool for environmental monitoring systems [13]. A number of related works can be found in the literatures. In the following two sections some closely related works on gas measurement system and water quality measurements systems are presented.

\section{A. Related Gas Measurements Systems}

One of the earliest works on radio-controlled aircraft based environmental monitoring system has been presented in [14]. The system has been designed to monitor the growth of plantation in a corn field. The aircraft is equipped with infrared camera and is flown over a cornfield to capture images on different days. Based on these captured images the system 
calculates so called Normalized Difference Vegetation Index (NDVI). The NDVI is then used to measure the growth rate of plantation.

A comprehensive greenhouse gas measurement system has been presented in [15]. The system consists of a carrier device, measurement system, and software program. The system is able to monitor a small area at low altitudes (under 500m above the ground level). The system is capable of measuring and recording air parameters like humidity, temperature, dust, radiation, and chemical pollution with a high geographical precision. It also supports rigorous data processing to obtain immediate information about the changes in air pollution level over the time. It also sends data to a ground monitoring system for generating a 3D map illustrating the distribution of pollution level over an area.

Many works use a fleet of UAVs instead of single UAV. A fleet of heterogeneous UAVs, with limited communication range, has been used in [16] to detect a pollution source over a large area. To fulfill this goal, the total observation area is divided into small areas and the UAVs are flown frequently over the areas. Once a source of pollution is detected, the whole fleet is informed about it. A sufficient (and necessary) condition has been derived for this purpose so that the whole fleet is informed about the pollution sources regardless of the propagation constraints. This kind of decentralization has been ensured through extensive simulation and pre-determined patrolling strategies.

Another similar work has been presented in [17]. In this work, a decentralized multiple-UAV approach has been used for perimeter surveillance. The perimeter surveillance has many applications including forest fire detection. Two basic perimeter topologies have been investigated in this work namely circular (no specific endpoints) and linear (double-back at endpoints). But, the most of work in [17] has been devoted to circular perimeter surveillance. The system is able to gather data at all points on the perimeter and transmit that data to a base station for analysis. In order to ensure accurate surveillance the UAVs are spread uniformly along the perimeter. A distributed algorithm has been developed that allows the UAVs to constantly gather data and send the data back to a base station while maintaining uniform spacing.

An autonomous distributed surveillance system, consisting of UAVs, wireless sensor/actuator networks, and ground camera networks, has been presented in [18]. The main goal of the system is to provide useful actuation capabilities involving multiple ground and aerial robots. The system architecture has been designed based on techniques namely task allocation, conflict resolution, task decomposition, and sensor data fusion. It satisfies two main requirements namely robustness and easy integration. The system has been designed to accomplish four different missions namely fire confirmation, surveillance, firefighter tracking, and load transportation.

Another similar system, based on coordination of aerial and ground robots, has been presented in [19]. The system is designed for surveillance and intervention in emergency management. The authors argued that task allocation strategy is an important part for this type of application. To solve this issue, a distributed market-based algorithm called $\mathrm{S}+\mathrm{T}$ has been presented in [19]. By using this algorithm the robots can provide transportation and 
communication relay services dynamically to other robots during a mission. The authors also present a demonstration that shows that the heterogeneous robots (aerial and ground) are able to cooperate in a mission to detect fire and extinguish the same.

Two UAVs have been used in [20] for rangeland mapping, assessment, and monitoring. Images of arid rangelands are acquired with two UAVs equipped with GPS guidance capability. The first UAV is a modified model airplane, which is able to fly along preloaded waypoints and acquire images with a digital camera. The second UAV has full autonomous flight capability and is equipped with color video and digital camera. Both systems acquire high-resolution images at 150m flying height. The acquired images have small footprint and hence an image processing algorithm has been introduced for mapping these images. The system is cost effective because a model airplane has been used to implement the system.

The work, presented in [21], is similar to this work. In [21] a prototype system has been presented for monitoring and computing greenhouse gases (GHGs). The UAV is deployed for collecting data from different nodes. This system uses the ZigBee technology that transfers data wirelessly to an UAV. The UAV also acts as a router and it sends data again to a data logger. In this system, an ATMEGA328P microcontroller has been used to compute air quality parameters such as $\mathrm{CO}_{2}, \mathrm{O}_{2}$, temperature, and humidity. All these parameters are measured on real time basis and are stored in an SD card for every 30 seconds interval. The data are then collected at several nodes. The results show that the system is able to trace and record air quality parameters with a high accuracy.

A solar powered UAV system has been presented in [22]. The system, integrated with a Wireless Sensor Network (WSN), measures greenhouse gases in agricultural lands. The system uses a generic gas sensing system for measuring $\mathrm{CH}_{4}$ and $\mathrm{CO}_{2}$ concentrations using infrared sensors. The major advantage of the system is that it is eco-friendly because of its solar power source. The system is also associated with a data management system that stores and analyzes the data. It also shares the information with operators and external users. The system has been tested and the test results show that it is able to collect the data and send the same to a central node. The central node is able to do further data analysis and generate 3D maps of the gases. The system is able to provide data relating to both temporal and spatial distribution of $\mathrm{CH}_{4}$ and $\mathrm{CO}_{2}$ in the atmosphere.

To measure atmospheric concentrations of released methane an UAV based system has been presented in [23]. This small drone is equipped with a gas detector to measure methane plume from a controlled release. The system has been commercially implemented by two companies namely Ventus Geospatial Inc. and Boreal Laser Inc. Hence, it is not cost effective. The field-test results indicate that the system is able to accurately locate the source of methane emission.

Another work, similar to our work, has been presented in [24]. In that work the design, construction, and validation of greenhouse gas monitoring system have been presented. The system consists of a sensory system placed on a four-rotor mini-UAV. The two fold objectives of the system are: (a) to measure temperature, humidity, luminosity, and $\mathrm{CO}_{2}$ concentration, (b) to produce the maps of these parameters. While designing the system, the sensors have 
been placed carefully considering the dynamics of quadrotor. The system has been tested through a set of field experiments in a real world greenhouse. The important contribution of this paper is that it shows a Quadrotor (if properly validated) can measure environmental variables with a high accuracy.

\section{B. Related Water Quality Measurement Systems}

The vehicles, used in water quality measurement system, can be classified as Surface Vehicle (SV) and Underwater Vehicle (UV). For example, a novel Autonomous Surface Vehicle (ASV) has been presented in [25]. The ASV is able to navigate through inland water storages and is able to measure water quality parameters and greenhouse gas emissions. It uses a storage scale of floating sensor network. The system is also equipped with laser based obstacle avoidance system and vision based inspection system so that it can navigate through complex inland water sources.

The underwater vehicles presented in [26] and [27] can dive up to 100m deep to monitor pollution, collect data, and capture video. Other efforts such NIMS system has been presented in [28]. The system explores semi-mobile sensor networks and supports adaptive sampling. The system is able to navigate for a long distance. However, it is time consuming and expensive to frequently deploy the system. On the other hand, the system presented in this paper can be carried in a backpack and can be quickly deployed to collect samples from multiple disconnected water sources. Further, in situ sampling unit presented in [29] cannot measure all desired water properties [29] such as suspended solids, pathogens, and heavy metals.

An eco-friendly fish culture using IT technology has been proposed in [30]. In this work, water quality data such as temperature, dissolved oxygen (DO), total dissolved solid (TDS), and salinity are acquired through sensors. The system then transfer the data to a remote location through a mobile terminal. If these parameters go beyond normal ranges, the system sends immediate alarm message to a user.

Another intelligent system, to monitor water quality from a remote location via SMS, has been presented in [31]. The system can monitor and record real-time data of two water quality parameters namely $\mathrm{pH}$ and DO levels. The related data are reported through centralized station using GSM network via SMS.

There is another work [32], similar to this work, has been done by the researchers at the University of Nebraska, and their approach is to fly with a small dangling pump. This work uses the flight dynamics of cable-suspended loads.

An aqua-copter has been used in [33] for measuring water quality. The system uses an UAV that lands in and takes off from a calm water surface. The major limitations of the system are: (1) fast-moving water and waves make it difficult to take off; (2) the sampling mechanism and battery enclosure are completely sealed and hence the system is not reusable.

The aim of work presented in [34] is to fly the UAV to a specified location for collecting water samples. As the vehicle navigates between sample locations, it can surmount obstacles such as dams, bridges, or land. The system pumps water and jettisons it overboard. While 
flying, it continuously monitors internal and external factors to determine the current risk level to avoid accident. Once the mission is complete, the system returns to a ground station. Then the operator swaps vials and initiates another mission. The main contributions of the work are: (1) developing a UAV-based system to obtain three $20 \mathrm{ml}$ water samples per flight, (2) integrating and characterizing sensors on the UAV to enable reliable and low-altitude flight $(1.0 \mathrm{~m}$ ) over water, (3) developing a framework to quantify risk, (4) testing the system indoors in a motion-capture room, and (5) characterizing the system outdoors in wind.

Most of the above mentioned works use high tech UAVs equipped with sophisticated sensors and instrument. Hence, implementation of these greenhouse gas monitoring systems are very expensive. Some other limitations incur because these existing systems are: (a) difficult to install: expert professionals are needed to install and configure the system, (b) difficult to use: control interfaces are not user friendly, and (c) non-customization: most of the systems are not customized on a user-need basis. On the other hand, most of the above mentioned water quality monitoring systems manually collect water samples from sites and measure water quality in the lab. The water quality data are then recorded. This technique of water quality testing is always tedious and error prone. It also requires considerable man-hours. Another limitation is that there is a time lag between the detection of water quality problem and corrective actions taken. During this time lag, the poor quality water continues polluting the distribution system and harming the environment.

\section{Methodology}

The section presents the system methodology and system components. The environmental monitoring system, presented in this work, consists of the following components (1) UAV, (2) gas measurement system, and (3) water quality measurement system. In this section, these three components are explained in details. Calibration method, whole system implementation, and cost analysis are also presented in this section.

\subsection{The UAV}

In this work Phantom 3 Advanced model has been used as the UAV. Some of the important parameters of this UAV are listed in Table 1. The UAV has some features that are very useful for this project. For example, it can reach remote places that are difficult to reach.

Table 1. The UAV Specifications [35]

\begin{tabular}{|l|c|}
\hline \multicolumn{1}{|c|}{ Parameters } & Values \\
\hline Weight (battery \& propeller included) & $1280 \mathrm{gm}$ \\
\hline Maximum Ascent Speed & $5 \mathrm{~m} / \mathrm{s}$ \\
\hline Maximum Descent Speed & $3 \mathrm{~m} / \mathrm{s}$ \\
\hline Maximum Speed & $16 \mathrm{~m} / \mathrm{s} \mathrm{(ATTI} \mathrm{Mode,} \mathrm{no} \mathrm{wind)}$ \\
\hline Maximum Flight Altitude & $6000 \mathrm{~m}$ \\
\hline Maximum Right Time & 23 minutes (approximately) \\
\hline Operating Temperature & $0-40^{\circ} \mathrm{C}$ \\
\hline GPS Mode & GPS/GLONASS \\
\hline Control Range & Pitch: $-90^{\circ}$ to $30^{\circ}$ \\
\hline
\end{tabular}


Among a number of Phantom models, the Phantom 3 Advanced has an intelligent flight mode as shown in Fig.1. The intelligent flight mode enables the UAV to auto take-off and land the aircraft with just a swipe of the finger on a smart device. One can track its position on a map. This map can also be used to set a new home point. One can even activate 'Return to Home' option to make flying easy and simple. This UAV can also capture shots and record videos.
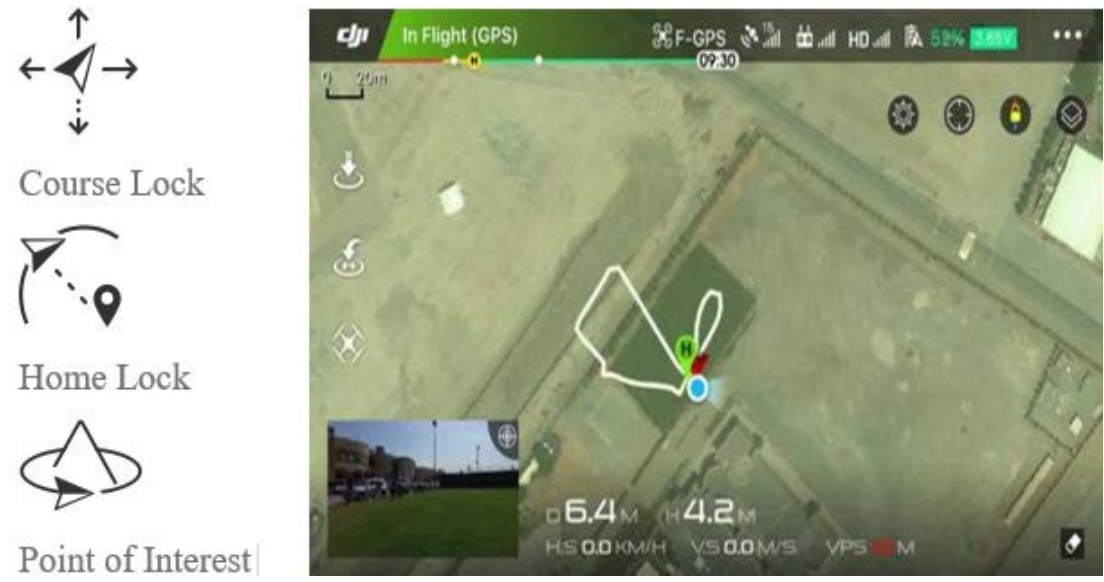

Figure 1. The flight modes in Phantom 3 Advanced.

The range, reliability, and video streaming quality of the Phantom 3 Advanced are much better than other existing models. The main reason is that the Phantom 3 Advanced uses a technology called Lightbridge. This technology can handle video and control signals. In good weather conditions, the Lightbridge allows the Phantom 3 Advanced to travel as far as $5000 \mathrm{~m}$ (3.1 miles) from the pilot. In other words, the Phantom 3 Advanced can travel over 4 times farther than other existing models. The Phantom 3 Advanced has some other excellent features such as GPS position hold, follow me, point of interest, waypoints, course lock, home lock, return to home, real-time battery monitoring, flight time estimation, stabilized video and photos, and manual camera exposure controls. The Phantom 3 Advanced is also able to avoid obstacles. It has two cameras - one is for video recording and the other one is for stabilization. With the Phantom 3 Advanced, almost all of the moving shots are done by manually moving sticks on the controller. This feature assists a new pilot to track the path of the UAV without making any jerky movements.

\subsection{The Gas Measurement System}

The gas measurement system consists of a microcontroller based monitoring unit mounted on the Quadcopter as shown in the block diagram presented in Fig. 2. The monitoring unit consists of microcontroller unit, wireless system, sensors, and storage device. The present work uses Arduino microcontroller because: (a) it is easy to find compatible hardware in the market, (b) it is simple to integrate with other hardware and software, and (c) it is easy to create a user-friendly interface with it.

Wireless networks and sensors are playing important roles in emerging pervasive computing technologies that are required for the efficient realization of monitoring and 


\section{Macrothink}

controlling system design. Effectively all wireless technologies, that support some form of remote data transferring, sensing, and controlling, can be included in a monitoring system. The present work uses the ZigBee wireless system. Compared to other wireless systems like Bluetooth and Wi-Fi, the ZigBee consumes low power. In addition, it aims at automation, whereas other two technologies aim at the connectivity of mobile devices in close proximity. Additionally, the ZigBee network supports devices with longer range.

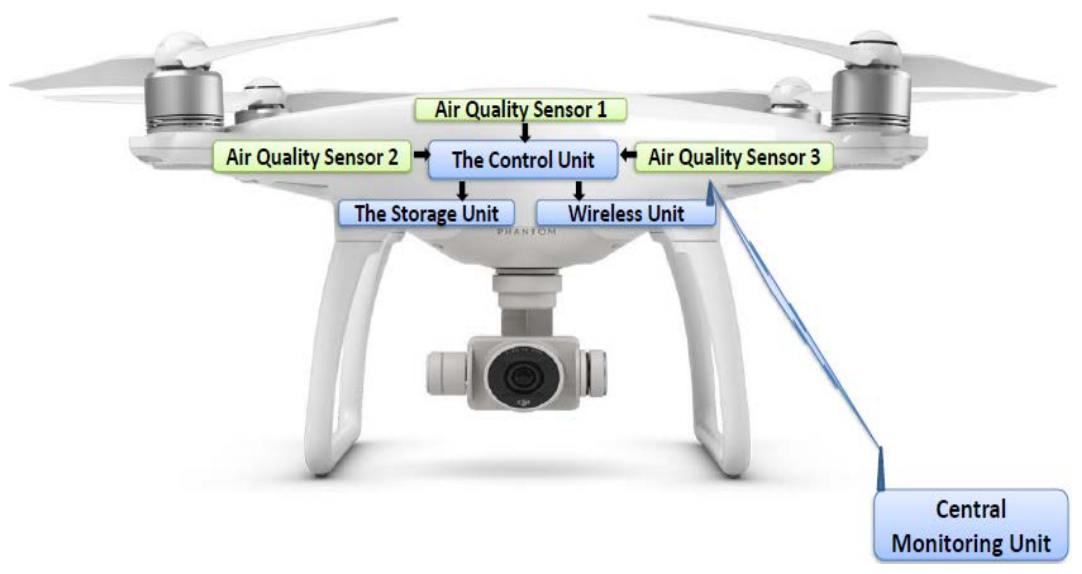

Figure 2. The gas measurement system.

Sensors are essential to collect the air quality data. They can sense certain gases and measure their concentrations. The sensors transform the changes in physical quantity into electrical signals. These sensors are associated with switching circuits. Based on the received signals these circuits operate. The sensors and switching circuits, used in the present system, can operate continuously to allow real time monitoring. The storage device (SD) ensures that all measured data are recorded. This allows efficient and accurate air quality monitoring even in the regions where wireless links are weak or 'broken'.

This work supports two options for data management. The UAV can be operated manually or automatically by waypoint as mentioned before. By using this option, these waypoints can be set on a map. The UAV then flies accordingly and measures air quality at different locations and at different altitudes. The system saves data in the SD card. After 2 minutes, the UAV flies to the next point and repeats the same procedure. After completing the mission, the UAV returns to its original location (i.e. home location). The complete flowchart for the gas measurement system is shown in Fig. 3. 


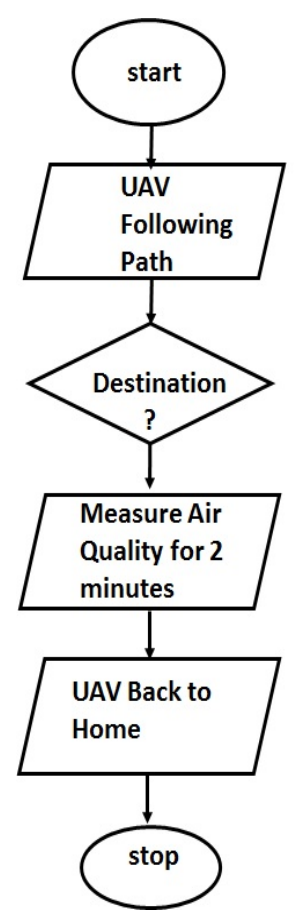

Figure 3. The whole procedure of the UAV during the air quality monitoring in a flowchart.

The gas measurement system consists of the following components (1) gas sensors $\left(\mathrm{O}_{3}\right.$, $\mathrm{CO}_{2}, \mathrm{CH}_{4}$ ), (2) temperature and humidity sensor, (3) pressure and humidity sensor, and (4) SD card module. The system presented in this work consists of five sensors as shown in Fig.4.

Compact, low power, and lightweight laser-based sensors have been used in this work for measuring gas species in the atmosphere. These sensors are designed specifically for the UAV application. The overall mass of the sensors is only 200 gms including batteries. Each sensor consumes less than $2 \mathrm{~W}$ of electrical power. The sensors are battery operated and they can be fully operational for a long time under diverse sensing environment. The sensors use a measurement technique, which is based on laser absorption spectroscopy. This technique uses a low power vertical cavity surface emitting laser (VCSEL) in the near-infrared spectral region. A VCSEL typically operates at 5-10 mA of current with a $5 \mathrm{~V}$ power supply to scan absorption features of atmospheric gaseous species of interest. The laser is operated from a Thorlab VTC002 diode laser current driver, thermo-electric cooler (TEC) module, and a custom electronic board for current sweep and modulation. The laser current ramp and sine modulator are developed using the XR2206CP function generator integrated circuits. Each sensor has its own characteristic curve for gas concentration. Once properly calibrated, these sensors can measure the desired gas concentration. Each sensor has a wide detection scope and high sensitivity to different gases. For example, the MQ 135 sensor has a high sensitivity to $\mathrm{CO}_{2}$. But, the MQ 131 has a high sensitivity to $\mathrm{O}_{3}$. Similarly, the MQ 4 has a high sensitivity to $\mathrm{CH}_{4}$. 


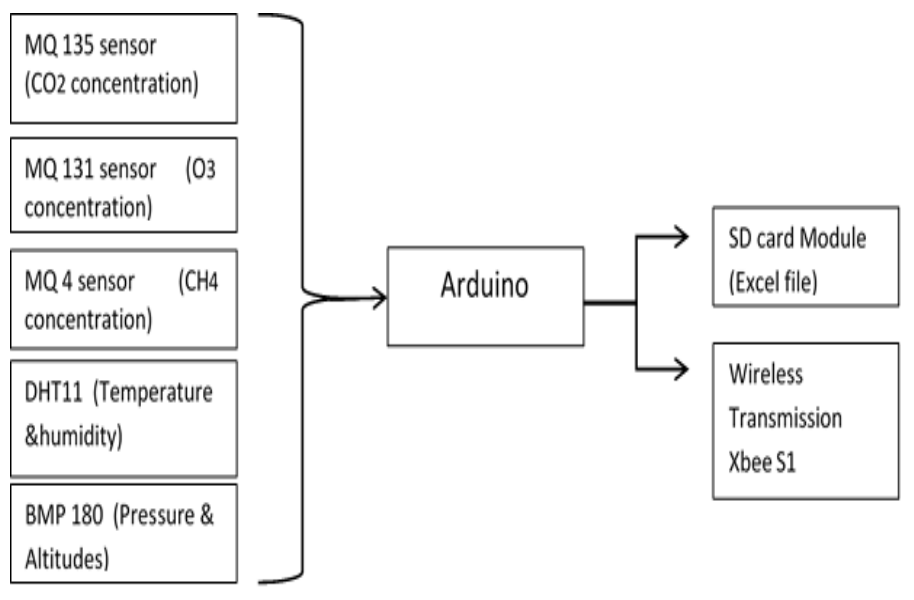

Figure 4. The gas measurement system.

Two other sensors namely DHT 11 sensor and BMP 180 sensor have been used in the system. The DHT 11 sensor is a digital temperature and humidity sensor. The DGT 11 sensor has an accuracy of $5 \%$ over temperature range of $0-50^{\circ} \mathrm{C}$ and the BMP 11 sensor has an accuracy of $2 \%$ over the humidity range of $20 \%-80 \%$. The BMP 180 sensor has a sensing range from $900 \mathrm{~m}$ to $500 \mathrm{~m}$ above the sea level, and a resolution of $(0.03 \mathrm{hPa} / 0.25 \mathrm{~m})$. The BMP 180 is used as temperature sensor. Since the pressure changes with altitude, this sensor has been used as an altimeter in this work.

\subsection{Gas sensor sensitivity and Calibration}

All the sensors used in this work have their own characteristics curve. To ensure that the sensors can measure gases with a high accuracy the sensors are calibrated before deployment. Regression analysis has been used for this purpose. The regression analysis has been done by extracting points from the sensitivity curve of the sensors. Then, an equation has been derived from these points and the equation has been used in the system for measuring the gas concentration.

In general, (1) expresses the greenhouse gas concentration

$$
\rho=A \times x^{B}
$$

, where $\rho$ is the gas concentration, $A$ is a scaling factor, $B$ is an exponent, and $x=R_{s} / R_{0}$. The resistance, $R_{s}$ is the sensor resistance and the resistance, $R_{0}$ is the clean room resistance. The (2) is used to calculate the sensor resistance $R_{s}$

$$
R_{s}=\left(\frac{V_{c c}}{V_{0}}-1\right) \times R_{L}
$$

, where $\mathrm{V}_{\mathrm{cc}}$ is the input voltage, $\mathrm{V}_{\mathrm{o}}$ is the output voltage, and $\mathrm{R}_{\mathrm{L}}$ is the load resistance $(10 \mathrm{~K} \Omega$ - $47 \mathrm{~K} \Omega$ ). The sensor resistance $\mathrm{R}_{0}$ is measured in a clean room condition. In this procedure, 


\section{Macrothink}

the sensor has been placed inside a clean room for 6-9 hours to find this resistance. The sensor generates an analog signal. Since the MCU can operate with digital signals, an Analog-to-Digital Converter (ADC) is used to convert this analog signal into a digital signal.

The data sheet of MQ 131 is shown in Fig.5. By extracting the points from the data sheet and plotting in using excel, the (3) is derived. A plot of (3) is shown in Fig. 6.

$$
\rho_{p p b}=24.986 \times\left(\frac{R_{s}}{R_{0}}\right)^{-1.289}
$$

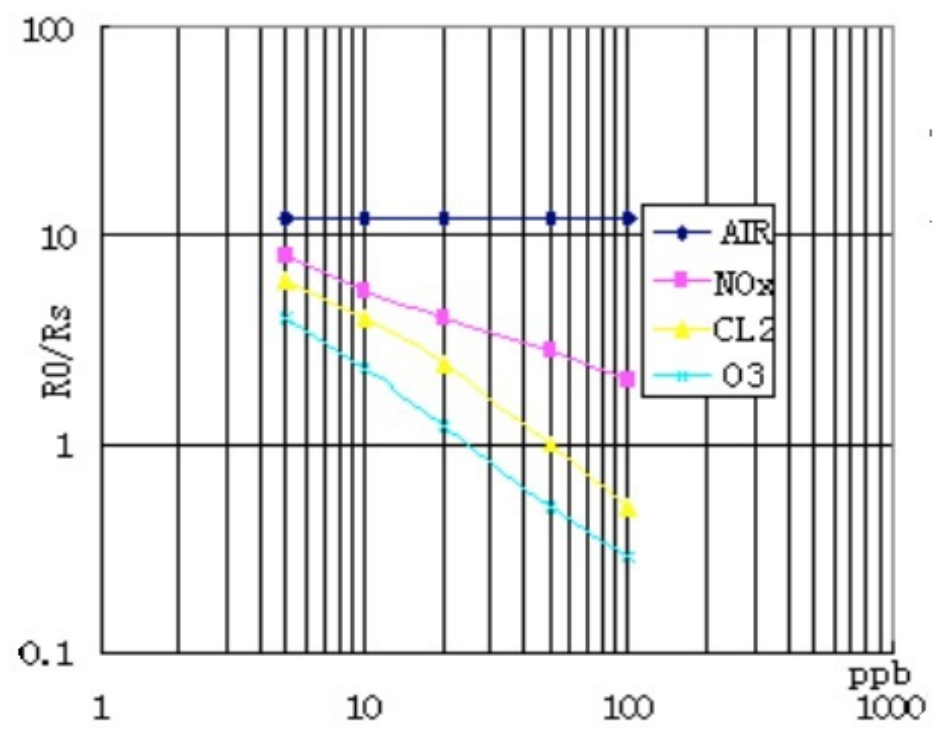

Figure 5. The MQ 131 Sensitivity Curve (Ozone).

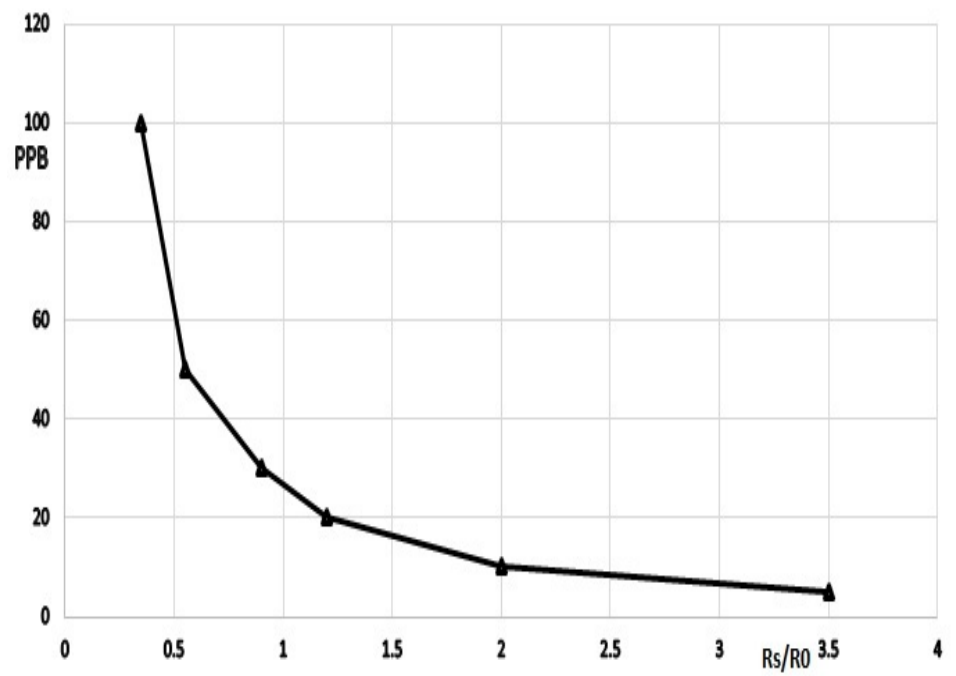

Figure 6. The plot of gas concentration (in PPB) against $R_{s} / R_{0}$ curve for MQ 131 sensor.

The same procedure is followed for the MQ 135 sensor. The data sheet of MQ 135 sensor is shown in Fig.7. By extracting the points from the data sheet and plotting using excel the (4) 


\section{Macrothink}

is derived. A plot of (4) is shown in Fig.8.

$$
\rho_{p p m}=108.6 \times\left(\frac{R_{s}}{R_{0}}\right)^{-2.696}
$$

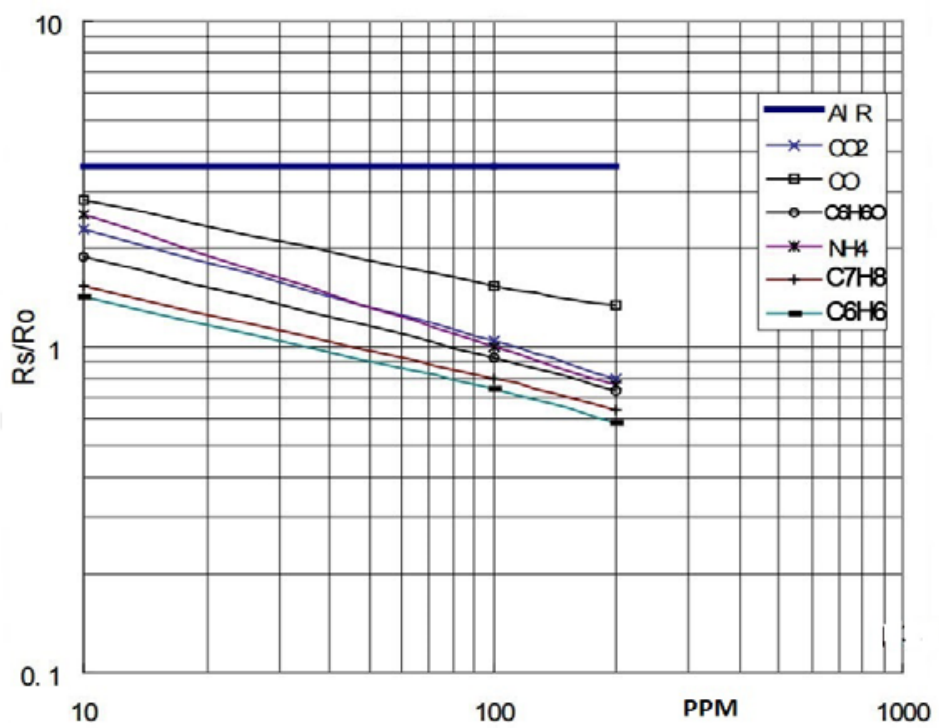

Figure 7. The MQ 135 sensitivity curve for $\mathrm{CO}_{2}$ gas sensor.

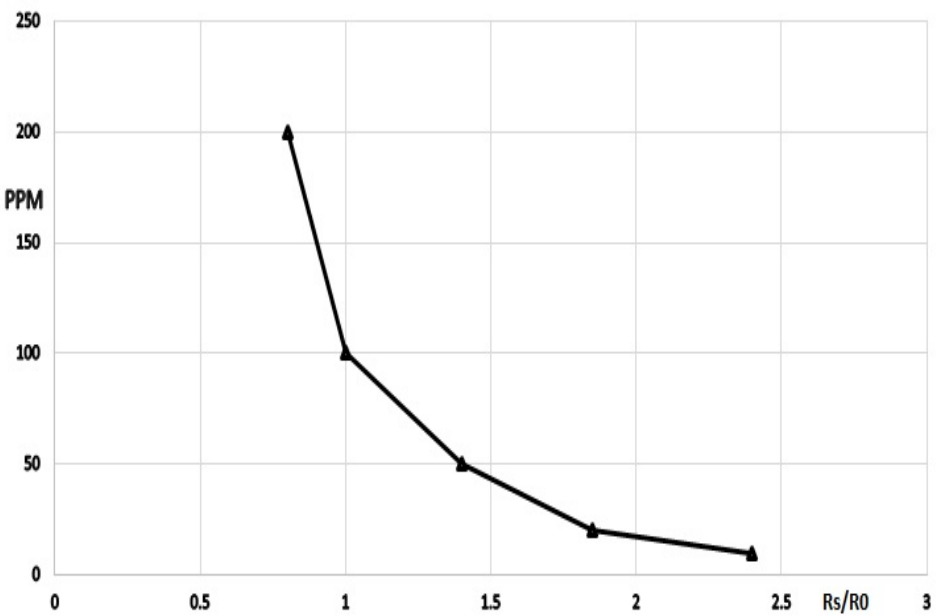

Figure 8. The gas concentration of $\mathrm{CO}_{2}$ (in PPM) against Rs/Ro curve for MQ 135 sensor.

Similarly, the data sheet of the MQ 4 sensor is shown in Fig. 9. By extracting the points from the data sheet and plotting a line using excel (5) is derived and a plot of (5) is shown in Fig.10. 


$$
\rho_{p p b}=1079.3 \times\left(\frac{R_{s}}{R_{o}}\right)^{-2.736}
$$

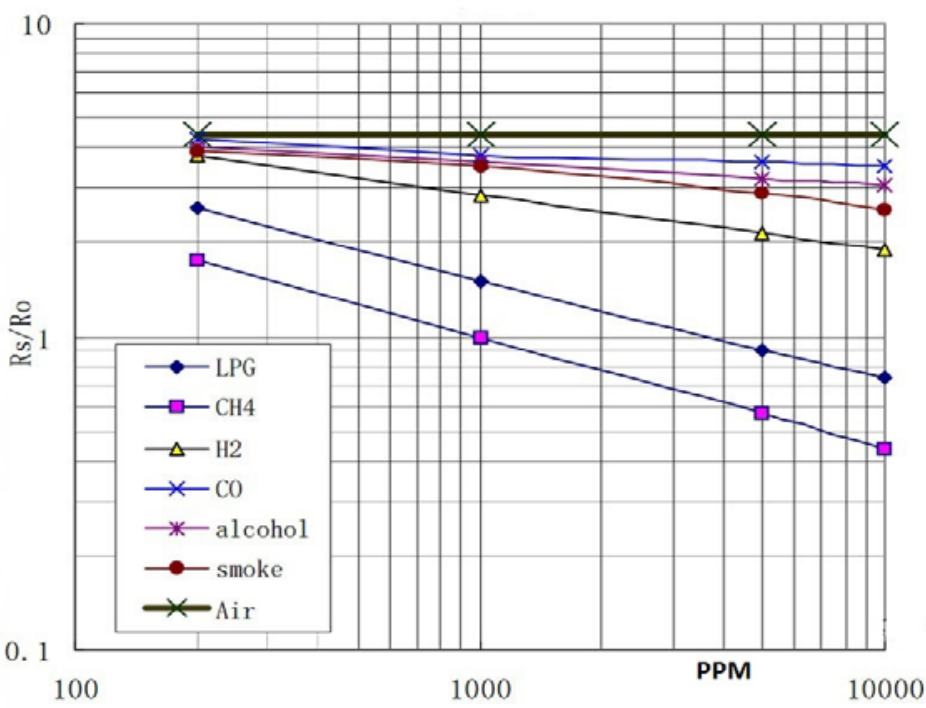

Figure 9. The sensitivity of the methane gas sensor.

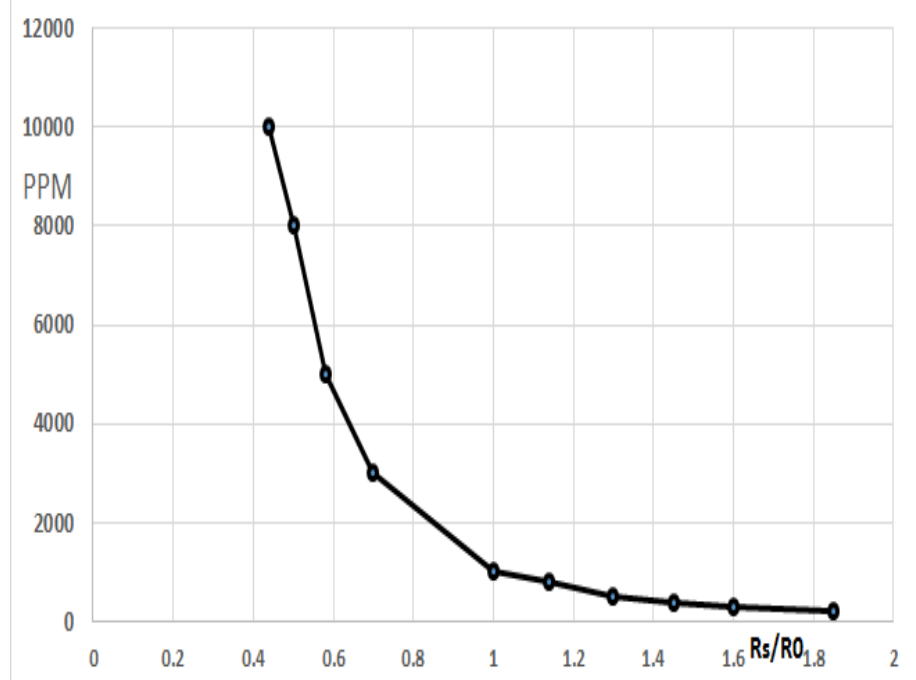

Figure 10. The methane gas concentration (in PPB) against Rs/Ro curve for MQ 4 sensor.

The sensor ionizes the gases while interacting with its constituents and adsorbing them by the sensing element (i.e., $\mathrm{SnO}_{2}$ ). This adsorption creates a potential difference on the element and this potential difference is sent to the processor unit through output pins in the form of current. For DHT11, a special library has been used to read the data from the sensor. 
For measuring the pressure using the BMP 180 sensor, a special library has been used to read the data from the sensor. Before measuring pressure one must take a temperature reading. The output temperature will be in degree Centigrade $\left({ }^{0} \mathrm{C}\right)$. The pressure is measured in millibar (mb). Based on the measured pressure, the altitude is calculated.

After measuring all these parameters (i.e., $\mathrm{CO}_{2}, \mathrm{CH}_{4}, \mathrm{O}_{3}$, temperature, humidity, pressure, and altitude), the data are saved in an SD card module. To save data into the SD card, the SD card library is used.

\subsection{The Transmission System}

The block diagram of data transmission system used in this work is shown in Fig.11. The Xbee has been used for data transmission. The Xbee supports a cheap and reliable wireless transmission. It supports both point-to-point protocol and mesh protocol. In this work, the point-to-point protocol has been used. The S1 version of Xbee has maximum outdoor range of $300 \mathrm{ft}(90 \mathrm{~m})$ and $250 \mathrm{kbps}$ data rate. A user can input date and time by using a keypad. An Arduino program has been developed to keep track of the time of measurement. The keypad used in this project is 3X4 keypad matrix. An LCD is used to display the date and time. The LCD used in this work is $16 \mathrm{X} 2$, which displays both date and time at the same time.

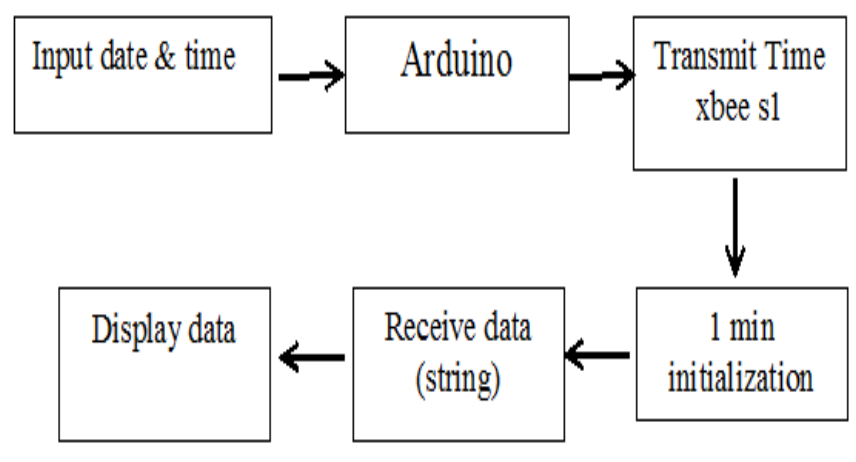

Figure 11. The system block diagram for data transmission.

\subsection{The Water Quality Measurement System}

The water quality monitoring system is another important component of the present system. The aim of the water quality monitoring system is to collect and monitor water quality data such as conductivity, salinity and TDS. The system consists of three subsystems namely (a) UAV with wireless system onboard. (b) water sampling unit, (c) sensor kit, (d) SD card, and (e) wireless unit.

A light water sampling unit has been designed for this purpose (see Fig. 12). By using this water sampling unit, the system can collect water sample from a water source and perform the necessary analysis. The UAV is sent to a water source by setting the longitude and latitude of the locations or by determining the places by the way-point option. When the UAV reaches a target location, it stays a little bit high above the water surface. Then the onboard Arduino sends a signal to a motor that moves the sampling system down into the water to collect the water sample. 


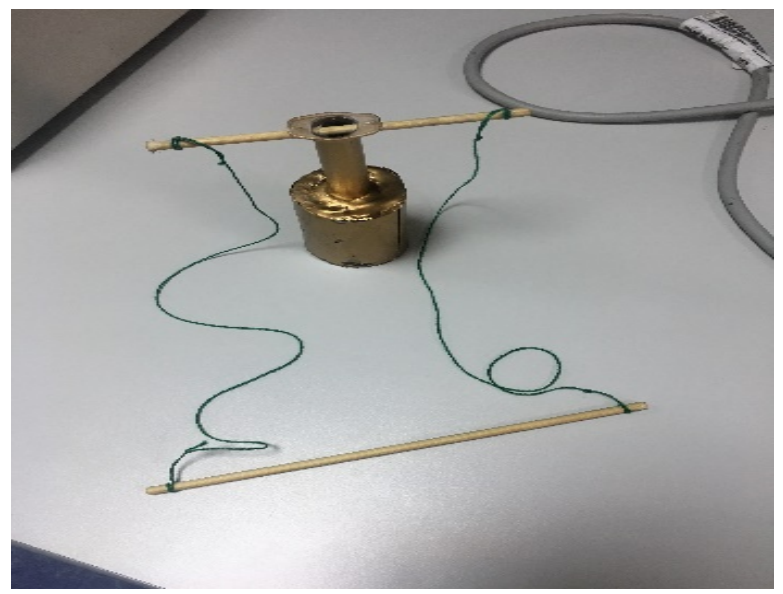

Figure 12. The simplest sampling system (rope and bottle).

While designing the water sampling system, a rope and a bottle have been used. Some metallic material was placed inside the bottle so that it can dive through the water. Finally, after collecting the water samples, the system can do the water quality analysis. Two options have been used for water analysis. The first option is that the UAV returns to the monitoring station with the water samples and the water is analyzed there. The other option is to do the analysis on site and send the data wirelessly to the monitoring station.

As mentioned above the water quality monitoring unit consists of microcontroller unit, wireless systems, water quality sensor kit, and storage device. In the present work, Arduino microcontroller is used. The system measures water quality with a sensor kit. The sensor kit contains sensors that measure four parameters including conductivity, salinity, TDS, and water gravity. The whole system has been designed and boarded in the UAV. Since the UAV can carry up to $1 \mathrm{~kg}$ for a flight duration of 23 minutes, the whole system is designed in way so that it weighs less than $1 \mathrm{~kg}$. The sensor kit is consisting of a set of high-quality sensors, which are very easy to calibrate. The sensor kit is connected to a microcontroller. The sensors are connected to the Arduino microcontroller and a program has been developed to measure the four quality parameters of water. This sensor kit is also upgradable and extendable so that more sensors can be added with the system in future. Only reprogramming of the Arduino is needed. For the measurement of TDS and salinity (6) and (7) have been used in the system.

Total dissolved solids (TDS) referenced to KCL is defined as

$$
\text { TDS }=-5.5886729 \times 10^{-12} C^{3}+1.573823009 \times 10^{-6} \times C^{2}+0.564100864 \times C-32.059899 \mathrm{mg} / \mathrm{L}
$$

The salinity is derived from the Practical Salinity Scale (PSS-78) and defined as

$$
S A L=0.012-0.2174 \times\left(\frac{C}{1000 \times 53.087}\right)^{1 / 2}+25.3283 \times\left(\frac{C}{1000 \times 53.087}\right)+13.7714 \times\left(\frac{C}{1000 \times 53.087}\right)-6.4788 \times\left(\frac{C}{1000 \times 53.087}\right)^{2}+2.5842 \times\left(\frac{C}{1000 \times 53.087}\right)^{2}
$$

, where $\mathrm{C}=$ conductivity of solution at $25^{\circ} \mathrm{C}(\mathrm{uS} / \mathrm{cm}), \mathrm{C}^{2}=$ conductivity raised to the power 2 , $\mathrm{C}^{3}=$ conductivity raised to the power of 3 and son on. The whole system operation is illustrated in the flow chart presented in Fig.13. The UAV starts its mission with following 


\section{Macrothink}

the path to reach the water sources. Then it stops and drops the sensor kit down. The sensor kit goes down until it touches the water and it keeps going down for another 10 second to reach the required depth. The sensor then starts measuring water quality parameters and saving them in the SD card. After 3 minutes, the sensor kit is pulled up again. This pulling operation is controlled by a micro-switch. At the end, the UAV returns to home location.

The operation of the system is illustrated in Fig.14(a). For measuring water quality parameters, the UAV is sent both manually and automatically to a water area. The UAV then goes down until it the sampling unit is able to collect the water sample. After collecting the sample, the UAV returns to its home location.

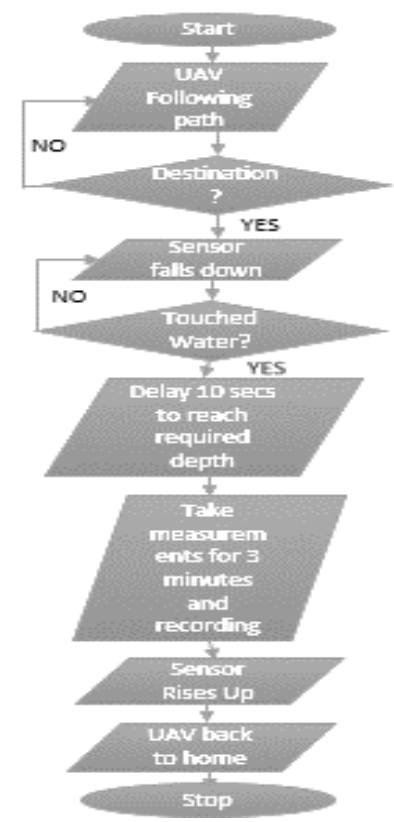

Figure 13. The whole procedure of the water monitoring system.

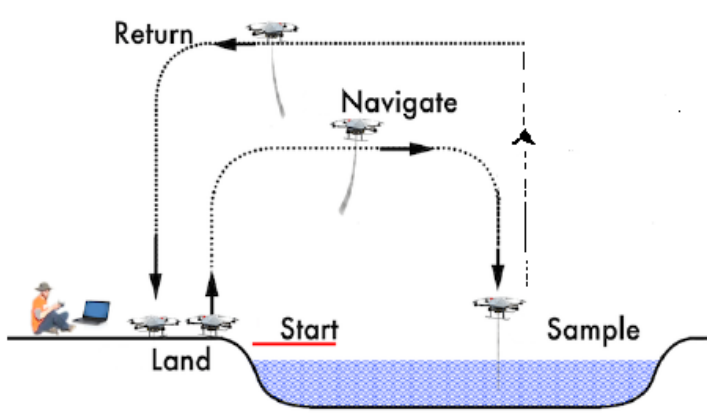

(a) Sample collection and return option 


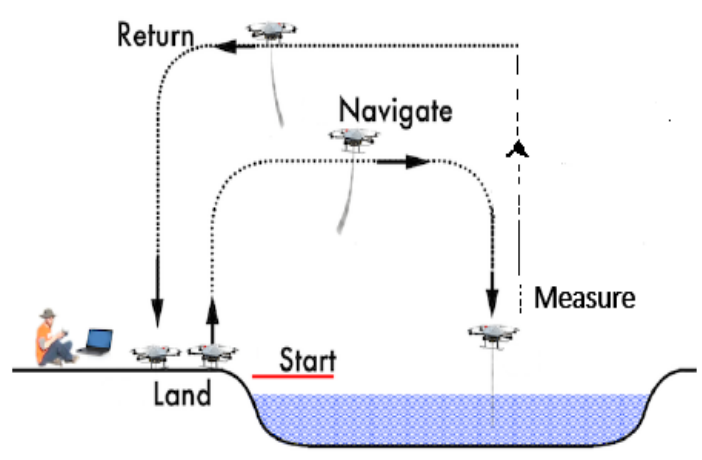

(b) Sample collection and on-site measurement

Figure 14. The movement of the UAV to take the sample and return back.

There is another technique of water quality monitoring used in this work is shown in Fig.14(b). The UAV is sent manually or automatically by waypoints that are marked on the map. The UAV stops at this point and sends the sensor kit down inside the water by motor and rope. The sensor then takes the measurements and saves the data in the SD card. The data can also be sent directly to the central monitoring unit. The system then pulls the sensor kit again and the UAV returns to home location.

By using the way-point flight mode in the Phantom 3 Advanced the UAV is sent automatically to different places (points). The way-point is a full-featured ground station application and it is very useful feature for this project. The water sources are marked as points and the UAV then navigate through each point for collecting water samples and measuring the water quality.

\subsection{The system cost analysis}

One of the main advantages of the present system is its low cost. Most of the existing systems, available in the literatures, use a very high tech UAV and expensive sensors. But, a cheap Quadcopter and cheap sensors have been used in this work. The project cost is summarized in Table 2. The tables show that the UAV is the most expensive component used in this project. It costs us AED 3100 (USD 840). The total cost of the project is AED 4500 (USD 1200).

Table 2. The categorized price distribution.

\begin{tabular}{|l|c|}
\hline \multicolumn{1}{|c|}{ Component } & Price (AED) \\
\hline UAV (Phantom 3 Advanced) & 3100 \\
\hline Sensors, motor, and other accessories & 500 \\
\hline Water Conductivity Sensor & 900 \\
\hline Total & $\mathbf{4 5 0 0}$ \\
\hline
\end{tabular}




\section{The Results}

This section presents some experimental data. The data are generated based on the measurement carried out at different locations. The air quality parameters have been measured at different altitudes and in different locations. Water quality parameters have been measured at different locations. In this section, these different measurement data are represented.

\subsection{Air quality data}

Air quality measurements are carried out in many locations in the local city (i.e., Fujairah). The results are listed in Table 3. The data presented in the Table 3 shows that the concentration of GHGs varies with respect location and time. The data have been compared among industrial area, beach, and city. The results are shown in Fig.15. It is depicted in this figure that the concentration of the GHGs is the lowest in the beach area. However, the same is the highest in the industrial zone. These values are low in the beach area because of the presence of sea water. The sea water has a property to absorb greenhouse gases in the air above it. On the other hand, the concentration of the GHGs in the industrial zones is the highest because of the high level of fossil fuel burnt in these zones.

Table 3. Measurements in City area (latitude: 25.121519, longitude: 56.339543) on Thursday 6/4/2017
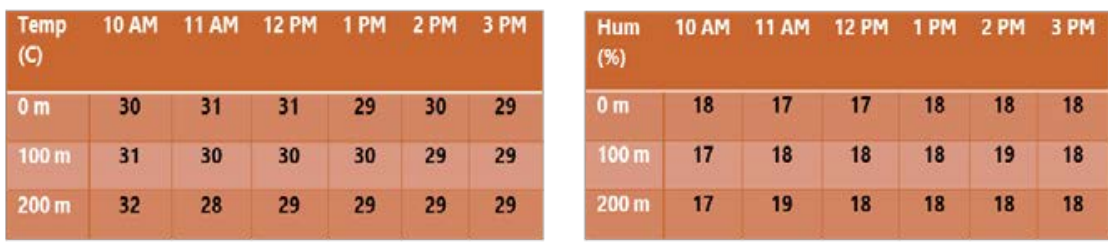

\begin{tabular}{|c|c|c|c|c|c|c|}
\hline Press (mbar) & $10 \mathrm{AM}$ & $11 \mathrm{AM}$ & $12 \mathrm{PM}$ & 1 PM & 2 PM & 3 PM \\
\hline $0 \mathrm{~m}$ & 1013.98 & 1014.06 & 1013.26 & 1013.19 & 1011.42 & 1011.68 \\
\hline $100 \mathrm{~m}$ & 1011.86 & 1011.81 & 1011.14 & 1010.90 & 1009.31 & 1009.32 \\
\hline $200 \mathrm{~m}$ & 1009.74 & 1009.74 & 1009.28 & 1009.16 & 1007.61 & 1007.56 \\
\hline
\end{tabular}

\begin{tabular}{|c|c|c|c|c|c|c|}
\hline $\mathrm{O} 3(\mathrm{PPB})$ & $10 \mathrm{AM}$ & $11 \mathrm{AM}$ & $12 \mathrm{PM}$ & $1 \mathrm{PM}$ & $2 \mathrm{PM}$ & $3 \mathrm{PM}$ \\
\hline $0 \mathrm{~m}$ & 56.80 & 49.56 & 42.86 & 27.00 & 30.54 & 34.04 \\
\hline $100 \mathrm{~m}$ & 51.72 & 49.45 & 38.93 & 26.03 & 28.76 & 28.58 \\
\hline $200 \mathrm{~m}$ & 45.84 & 35.12 & 24.94 & 23.52 & 27.68 & 25.36 \\
\hline
\end{tabular}

\begin{tabular}{|c|c|c|c|c|c|c|}
\hline Methane (PPB) & $10 \mathrm{AM}$ & $11 \mathrm{AM}$ & $12 \mathrm{PM}$ & $1 \mathrm{PM}$ & 2 PM & 3 PM \\
\hline $0 \mathrm{~m}$ & 1198.13 & 904.10 & 930.65 & 998.66 & 1008.31 & 986.00 \\
\hline $100 \mathrm{~m}$ & 1055.60 & 817.32 & 900.05 & 991.99 & 1005.29 & 902.50 \\
\hline $200 \mathrm{~m}$ & 1009.67 & 789.84 & 852.28 & 827.00 & 954.47 & 871.51 \\
\hline
\end{tabular}

\begin{tabular}{|c|c|c|c|c|c|c|}
\hline $\mathrm{CO} 2$ (PPM) & $10 \mathrm{AM}$ & $11 \mathrm{AM}$ & $12 \mathrm{PM}$ & $1 \mathrm{PM}$ & $2 \mathrm{PM}$ & $3 \mathrm{PM}$ \\
\hline $0 \mathrm{~m}$ & 320.00 & 217.24 & 232.15 & 232.15 & 246.34 & 198.46 \\
\hline $100 \mathrm{~m}$ & 298.96 & 213.63 & 224.60 & 198.00 & 198.80 & 194.38 \\
\hline $200 \mathrm{~m}$ & 224.42 & 161.88 & 164.80 & 153.36 & 150.86 & 167.76 \\
\hline
\end{tabular}




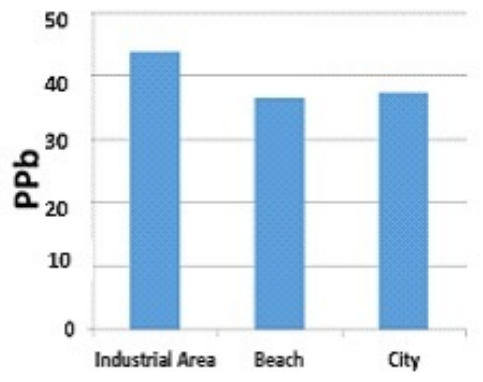

(a) Concentration of $\mathrm{O}_{3}$

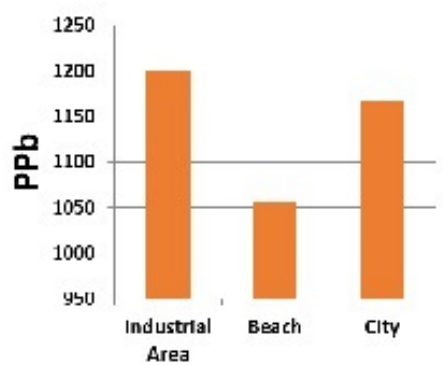

(b) Concentration of $\mathrm{CH}_{4}$

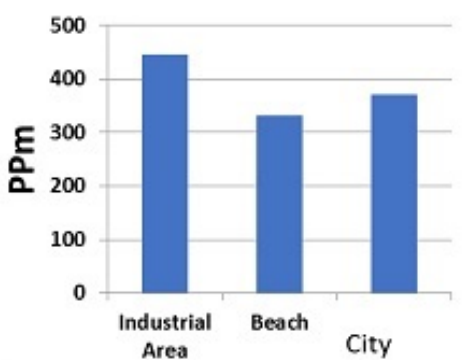

(c) Concentration of $\mathrm{CO}_{2}$

Figure 15 . The results of the air quality parameters in three main areas.

\subsection{Water Quality Monitoring}

In order to ensure the reliability in water quality measurement, the system has been tested with different liquids and the data are then compared with the suppliers' data. We discover that the data produced by the present system and the same supplied by the manufacturing are closely matched with a high accuracy. The data also show that the conductivity, TDS, salinity, and gravity of clean water are much lower than the same of household tap water and commercially available Carrefour water (i.e. water manufactured by a local company). The system has also been tested to measure the water quality at different locations in Gulf of Oman. The coordinates of these locations are shown in Fig.16. The data of these locations are listed in Table 5. The data show that the water quality parameters vary widely depending on locations even within a short range.

Table 4. The four water quality parameters of seven different liquids.

\begin{tabular}{|l|c|c|c|c|c|c|c|}
\hline Parameters & Clean Water & $\mathbf{N a O H}$ & $\mathbf{1 2 8 8 0} \boldsymbol{\mu S}$ & $\mathbf{8 0 0 0 0} \boldsymbol{\mu S}$ & Tap Water & Carrefour Water & Coffee \\
\hline $\begin{array}{l}\text { Electrical } \\
\text { conductivity }\end{array}$ & 178 & 18060 & 11900 & 72000 & 440 & 190 & 2187 \\
\hline TDS & 96 & 9750 & 6450 & 39044 & 234 & 106 & 1170 \\
\hline Salinity $(\mu \mathrm{S} / \mathrm{cm})$ & 0.00 & 10.67 & 6.80 & 42 & 0.20 & 0.00 & 1.10 \\
\hline Gravity & 1.00 & 1.009 & 1.005 & 1.036 & 1.00 & 1.00 & 1.001 \\
\hline
\end{tabular}




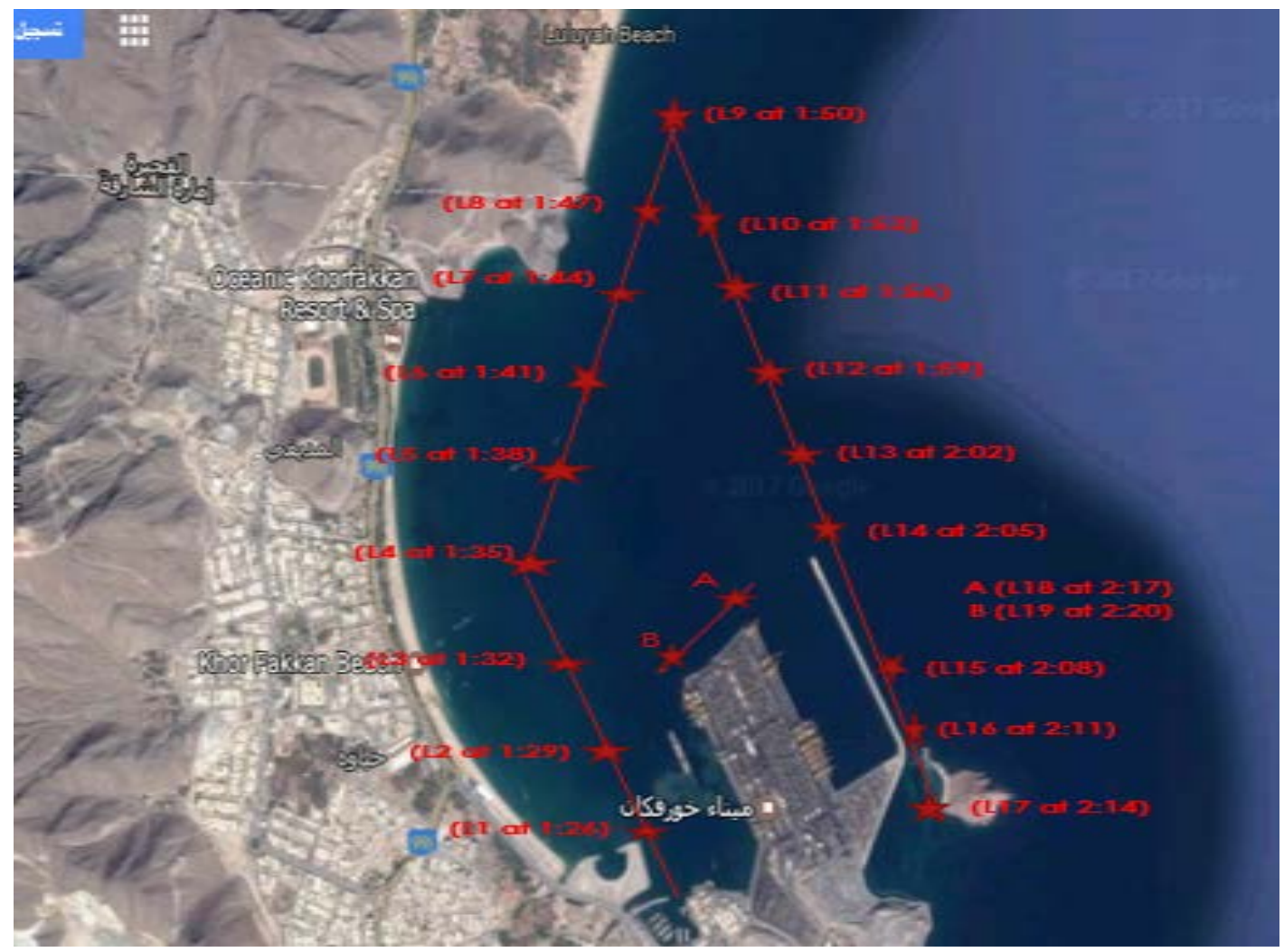

Figure 16. Locations and times of water quality measurements in Oman Sea.

Table 5. Water quality parameters in different locations of Oman Sea.

\begin{tabular}{|c|c|c|c|c|c|c|c|c|c|c|}
\hline & $\begin{array}{c}\mathrm{L} \\
(25.351890 \\
56.360441)\end{array}$ & $\begin{array}{c}12 \\
(25.355026, \\
56.358578)\end{array}$ & $\begin{array}{c}\mathbf{L 3} \\
(25.358545 \\
56.356461)\end{array}$ & $\begin{array}{c}14 \\
(25.362675 \\
56.354851)\end{array}$ & $\begin{array}{c}\text { L5 } \\
\text { (25.366117, } \\
56.354427)\end{array}$ & $\begin{array}{c}16 \\
(25.369866 \\
56.357305)\end{array}$ & $\begin{array}{c}17 \\
(25.373920 \\
56.359167)\end{array}$ & $\begin{array}{c}18 \\
(25.376980 \\
56.360268)\end{array}$ & $\begin{array}{c}\text { L9 } \\
(25.380713, \\
56.361616)\end{array}$ & $\begin{array}{c}\mathrm{L10} \\
(25.377309 \\
56.364613)\end{array}$ \\
\hline$E C(\mu s / \mathrm{cm})$ & 51780 & 51500 & 53000 & 52870 & 52890 & 51980 & 53900 & 52680 & 52660 & 52660 \\
\hline TDS (PPM) & 27940 & 27800 & 28640 & 28544 & 28556 & 28067 & 29100 & 28460 & 28440 & 28427 \\
\hline Salinity (PPT) & 34.00 & 33.88 & 35.00 & 34.79 & 34.85 & 34.17 & 35.5 & 34.73 & 34.70 & 34.70 \\
\hline \multirow[t]{2}{*}{ Gravity } & 1.025 & 1.025 & 1.026 & 1.026 & 1.026 & 1.025 & 1.026 & 1.026 & 1.026 & 1.026 \\
\hline & $\begin{array}{c}L 11 \\
(25.374213, \\
56.363154)\end{array}$ & $\begin{array}{c}\text { L12 } \\
(25.370887, \\
56.364610)\end{array}$ & \multicolumn{2}{|c|}{$\begin{array}{c}\mathrm{L13} \\
(25.367562 \\
56.367606)\end{array}$} & $\begin{array}{c}\mathrm{L} 14 \\
(25.362846 \\
56.370346)\end{array}$ & $\begin{array}{c}\text { L15 } \\
\text { (25.357561, } \\
56.374056)\end{array}$ & $\begin{array}{c}\text { L16 } \\
(25.356736, \\
56.373940)\end{array}$ & $\begin{array}{c}117 \\
(25.352328 \\
56.374368)\end{array}$ & $\begin{array}{c}118 \\
(25.361453, \\
56.364868)\end{array}$ & $\begin{array}{c}L 19 \\
(25.359210, \\
56.362386)\end{array}$ \\
\hline $\mathrm{EC}(\mu \mathrm{s} / \mathrm{cm})$ & 53010 & 53360 & \multicolumn{2}{|c|}{52250} & 51840 & 53010 & 52780 & 54650 & 52720 & 51990 \\
\hline TDS (PPM) & 28625 & 28820 & \multicolumn{2}{|c|}{28210} & 27995 & 28638 & 28504 & 29516 & 28473 & 28110 \\
\hline Salinity (PPT) & 34.91 & 35.24 & \multicolumn{2}{|c|}{34.42} & 34.16 & 34.96 & 34.91 & 36.19 & 34.75 & 34.30 \\
\hline Gravity & 1.026 & 1.026 & \multicolumn{2}{|c|}{1.026} & 1.025 & 1.026 & 1.026 & 1.027 & 1.026 & 1.026 \\
\hline
\end{tabular}

\section{Conclusion}

In this work, we present a reliable and low cost environmental monitoring system using UAV. The system is able to measure air quality at different altitudes that are hard to reach by 
conventional air quality monitoring system. The system is also able to collect water sample from on-shore and off-shore water sources and measure the quality of sampled water. We test the system and the results show that the system is capable of sending the data to a local monitoring unit through a wireless system. Moreover, the system is to store data in a SD card. The system uses low cost components and hence it is cheap (around USD 1250) compared to other existing system. This paper also presents some sample data.

There are several limitations of the present system. One of the limitation is that we measure air and water quality in few selected locations. In order to determine the environmental pollution level in the Arabian Gulf region we need generate comprehensive data for the same. Another major limitation is that we use commercially available sensors in our work. Recently, many low cost and reliable sensors have been designed [36-37]. In our future work, we need to these sensors in the present system. We also need to develop an algorithm for the flight path for the UAV so that we can cover a given region. We will use a fleet of UAVs instead of single UAV. We also need to develop a program that will process the data and will generate pollution map for this region. We have left all these for our future works.

\section{References}

[1] Mitchell, J.F.B “The Greenhouse Effects and Climate Change”, Reviews of Geophysics, Vol.7, No. 1, February 1989, pp. 115-139 https://doi.org/10.1029/RG027i001p00115

[2] Bessoui C., Ferchaud F., Gabrielle B., Mary B., "Biofuels, greenhouse gases and climate change. A review”, Agronomy Sust. Developm. (2011) 31: 1, pp. 1-80 https://doi.org/10.1051/agro/2009039

[3] United States Enviromental Protection Agency, “Climate Change and Ecosystem”, Retrieved from https://www.epa.gov/sites/production/files/signpost/cc.html accessed on June 22,2017

[4] National Oceanic and Atmospheric Administration, “ Ecological Impacts of Climate Change”, Retrieved from https://pdfs.semanticscholar.org/b97c/5c098f9182886d0a4631108251d2ae0790f9.pdf accessed on January 15, 2018

[5] US National Climate Assessment, "Climate Change Impacts in United States” Retrieved from http://s3.amazonaws.com/nca2014/low/NCA3_Highlights_LowRes.pdf?download=1, accessed on January 15, 2018

[6] New York Times Environment, Retrived http://www.nytimes.com/2013/10/10/science/earth/by-2047-coldest-years-will-be-warm er-than-hottest-in-past.html , accessed on January 15, 2018

[7] Leggett J.A., "Federal Citations to the Social Cost of Greenhouse Gases”, Report of Congressional Research Service available at https://fas.org/sgp/crs/misc/R44657.pdf accessed on January 15, 2018

[8] Moorehead J. and Nixon T., "Global 500 Greenhouse Gases Performance 2010-2015 : 2016 Report on Trends”, A Thomson Reuters Financial and Risk White Paper available 
at

https://www.thomsonreuters.com/content/dam/openweb/documents/pdf/corporate/Repo rts/global-500-greenhouse-gases-performance-2010-2015.pdf accessed on January 15, 2018

[9] Progress on Drinking Water and Sanitation, Update and MDG Assessment, 2015, available at http://www.who.int/water_sanitation_health/ accessed on January 10,2018

[10] Facts About Water and Sanitization available at http://water.org/water-crisis/water-sanitation-facts/ accessed on January 05, 2018

[11] World Economic Forum. Global Risks 2015 Report, 2015 available at http://www3.weforum.org/docs/WEF_Global_Risks_2015_Report15.pdf accessed on January 15,2018

[12] Association for Unmanned Vechicle Systems International, “The Benefits of Unmanned Aircraft Systems: Saving Time, Saving Money, Saving Lives”, Retrieved from https://epic.org/events/UAS-Uses-Saving-Time-Saving-Money-Saving-Lives.pdf accessed on January 15, 2018

[13] Satterlee L., "Climate Drones: A New Tool for Oil and Gas Air Emission Monitoring”, Environmental Law Institute, Washington DC, 2016 Retrieved from http://www.eli.org/sites/default/files/elr/featuredarticles/46.11069.pdf accessed on January 15, 2018

[14] Raymond H.E., Daughtry C. S.T, Walthall C.S., McMurtrey J.E., Dulaney W.P., “Agricultural Remote Sensing using Radio Controlled Model Aircraft”, Digital Imaging and Spectral Techniques: Applications to Precision Agriculture and Crop Physiology, ASA-CSSA-SSSA, Madison, WI, pp. 197-205, 2003.

[15] Molnár1 A., “A Multi-rotor System for the Collection and Analysis of Measurements to Evaluate and Spatially Demonstrate the Pollutants in the Air”, International Journal of Advanced Robotic Systems, 2015, 12:187 https://doi.org/10.5772/61229

[16] Acevedo J. J., Arrue B. C., Diaz-Banez J. M., Ventura I., Maza I., Ollero, A., "Decentralized strategy to ensure information propagation in area monitoring missions with a team of UAVs under limited communications”, Unmanned Aircraft Systems (ICUAS), 2013 International Conference on, pp. 565-574, 2013. Available at http:/doi.org/10.1109/ICUAS.2013.6564734

[17] Kingston D., Beard R. W., Holt R., "Decentralized perimeter surveillance using a team of UAVs”, Robotics, IEEE Transactions on, Vol. 24, No. 6, pp. 1394-1404, 2008, https://doi.org/10.1109/TRO.2008.2007935

[18] Maza I., Caballero F., Capitan J., Martinez-de-Dios J. R., and Ollero A., “A distributed architecture for a robotic platform with aerial sensor transportation and self-deployment capabilities”, Journal of Field Robotics, Vol. 28, No. 3, pp. 303-328, 2011, https://www.doi.org/10.1002/rob.20383

[19] Viguria A., Maza I., Ollero A., "Distributed service based cooperation in aerial/ground robot teams applied to fire detection and extinguishing missions”, Advanced Robotics, Vol. 24, No. 1-2, pp. 1-23, 2010, https://doi.org/10.1163/016918609X12585524300339

[20] Laliberte A. S., Rango A., Herrick J. E., “Unmanned Aerial Vehicles for rangeland mapping and monitoring : A comparison of two systems”, Proceedings of the American 
Society for Photogrammetry and Remote Sensing Annual Conference, Tampa, FL,2007, https://jornada.nmsu.edu/files/bibliography/07-033.pdf accessed on January 16,2018

[21] Sidek O., Abdullah A., Za’bah U.N., Amran N.A., et. al, “ Development of Prototype System for Monitoring and Computing Greenhouse Gases with Unmanned Aerial Vehicle (UAV) Deployment”, Proceedings of International Symposium on Technology Management and Emerging Technology, May 27-29, Bandung, Indonesia, pp. 98-101, https://doi.org/10.1109/ISTMET.2014.6936486

[22] Malaver A.J. R., Gonzalez L.F., Motta M., et. al, "Design and flight testing of an integrated solar powered UAV and WSN for greenhouse gas monitoring emissions in agricultural farms”, Proceedings of IEEE/RSJ International Conference on Intelligent Robots and Systems, IEEE, Congress Centre Hamburg, Hamburg, Germany, pp. 1-6,

[23] Hugenholtz C., and Barchyn, T., “ A Drone in Search of Methane”, Project Summary February 2016, University of Calgary available at http://ventusgeo.com/wp-content/uploads/2016/04/Project_outline_no_watermark-1.pdf accessed on January 16, 2018

[24] Roldán J.J., Joossen G., Sanz D., Cerro J., and Barrientos A.,” Mini-UAV Based Sensory System for Measuring Environmental Variables in Greenhouses”, Sensors 2015, 15, pp. 3334-3350 https://doi.org/10.3390/s150203334

[25] Dunbabin M., Grinham A., and Udy J., “An autonomous surface vehicle for water quality monitoring," Australian Conference on Robotics and Automation, Sydney, Australia, December 2-4, 2009, vol. 2009, http://www.araa.asn.au/acra/acra2009/papers/pap155s1.pdf

[26] Cruz N.A. and Matos A.C., “The MARES AUV, a Modular Autonomous Robot for Environment Sampling," Proceedings of IEEE OCEANS, Quebec City, QC, Canada, September 15-18 2008, pp. 1-6, https://doi.org/10.1109/OCEANS.2008.5152096

[27] Melo J. and Matos A., "Bottom estimation and following with the MARES AUV”, Proceedings of IEEE Oceans, Hampton Roads, VA, USA 2012, October 14-19, 2012, pp. 1-8 https://doi.org/10.1109/OCEANS.2012.6404917

[28] Rahimi M., Pon R., Kaiser W., Sukhatme G., Estrin D., and Srivastava M., “Adaptive sampling for environmental robotics," Proceedings of the IEEE International Conference on Robotics and Automation, New Orleans, LA, USA, USA, 26 April-1 May 2004, Vol. 4, 2004, pp. 3537-3544, https://doi.org/10.1109/ROBOT.2004.1308801

[29] Erickson A.J, Weiss P.T., and Gulliver J.S., "Water sampling methods," in Optimizing Storm water Treatment Practices. Springer New York, Jan. 2013, pp. 163-192, https://doi.org/10.1007/978-1-4614-4624-8_10

[30] Ceong H., Park J.S., and Han S., “IT convergence application system for eco aquafarm”, Proceedings of the IEEE Frontiers in the Convergence of Bioscience and Information Technologies, Jeju City, October 11-13, 2007, pp. 878-883 https://doi.org/10.1109/FBIT.2007.75

[31] Mohd S.S., "Intelligent Aquaculture System via SMS”, University of Teknology. Petronas, Malaysia, 2007.

[32] Sreenath K., Michael N., and Kumar V., "Trajectory generation and control of a quadrotor with a cable-suspended load-a differentially-flat hybrid system.” Proceedings 


\section{Macrothink}

of the IEEE International Conference of Robotics and Automation, Karlsruhe, Germany, 6-10 May 2013,pp. 4888-4895, https://doi.org/10.1109/ICRA.2013.6631275

[33] “Aquacopters.” [Online]. Available: http://www.aquacopters.com

[34] Ore J.-P., Elbaum S., and Detweiler C., “Autonomous Ariel Water Sampling”, Computer Science and Engineering, University of Nebraska, Lincoln, Nebraska, USA available at http://cse.unl.edu/ carrick/papers/OreEBZD-FSR2013.pdf accessed on January 16, 2018

[35] Phantom 3 Advanced Specifications https://www.dji.com/phantom-3-adv/info accessed on January 17, 2018

[36] Parra, L., Ortuño, V., Sendra, S., and Lloret, J. , "Two new sensors based on the changes of the electromagnetic field to measure the water conductivity", Proceedings of the Seventh International Conference on Sensor Technologies and Applications (SENSORCOMM 2013), Barcelona, Spain ,Vol. 2531, p. 266-272

[37] Sendra, S., Parra, L., Ortuño, V., and Lloret, J., "A low-cost turbidity sensor development", Proceedings of the 7th International Conference on Sensor Technologies and Applications (SENSORCOMM'13) , Wellington, New Zealand, December 03-05, pp. 266-272

\section{Copyright Disclaimer}

Copyright reserved by the author(s).

This article is an open-access article distributed under the terms and conditions of the Creative Commons Attribution license (http://creativecommons.org/licenses/by/3.0/). 